\title{
Case report: In-stent thrombosis and clopidogrel resistance in ST-segment myocardial infarction followed by reinfarction
}

\author{
Zorin Makarović*, Robert Steiner, Sandra Makarović, Damir Kirner, Ivica Bošnjak \\ University Hospital Center Osijek, Osijek, Croatia
}

62-years old man was admitted in coronary care unit with ST-segment myocardial infarction of anteroseptal and lateral walls. Emergency coronarography showed occlusion of LAD, Cx on distal segment showed significant stenosis $(80 \%), \mathrm{RCA}$ in middle segment showed non significant plaque. Coronarography was followed by $\mathrm{PCl}$ procedure of LAD and implantation of two stents, on proximal and middle segment of LAD. Result was successful. Patient was stable afterwards, until third day, when he felt chest pain. ECG showed ST-segment elevation in anteroseptal and lateral leads. Emergency coronarography showed occlusion of proximal $L A D$, in proximal stent with new occurring thrombus. Balloon dilatation of in-stent segment was done, which was followed by opening of LAD. Crossing middle to distal segment showed significant stenosis, which was followed by balloon dilatation. Finally balloon dilatation with $\mathrm{NC}$ balloon was done. The result was successful. Afterward he was stable. Seven days after procedure he was released home with recommendation to use clopidogrel $150 \mathrm{mg}$ and aspirin 100 mg. Second day after release from hospital, he felt again chest pain, and was admitted in coronary care unit with anteroseptal and lateral ST-segment elevation on ECG. Emergency coronarography showed subostial LAD occlu- sion. Primary PCI LAD was done with stenting of ostial LAD with bare metal stent. Result was successful. Thrombocyte aggregation tests were done (aggregation test with colagen, ADP and ristocetin). Results showed that thrombocyte aggregation in ADP test was within referent values, which points absence of thrombocyte inhibition by clopidogrel. Considering clopidogrel resistance, he was given ticagrelor. Further he was hemodynamic stable without chest pain. He was released home and doing well thereafter.

KEYWORDS: in-stent thrombosis, percutaneous coronary intervention, clopidogrel, ticagrelor.

\section{Received: $3^{\text {rd }}$ Mar 2013}

${ }^{*}$ Address for correspondence: Klinički bolnički centar Osijek, J. Hutlera 4, HR-31000 Osijek, Croatia.

Phone: +385-31-511-511

E-mail: zorinmakarovic2@net.hr

\section{Literature}

1. Dinicolantonio JJ, Serebruany VL. Exploring the reduction in myocardial infarctions in the PLATO trial: Which patients benefited on ticagrelor vs. clopidogrel? Int J Cardiol. 2012 Dec 26. doi: 10.1016/j.jijcard.2012.11.110.

2. Van Buuren F, Dahm JB, Horskotte D. Stent restenosis and thrombosis: etiology, treatment, and outcomes. Minerva Med. 2012;103(6):503-11.

3. Gurbel PA, Antonino MJ, Bliden KP, Dichiara J, Suarez TA, et al. Platelet reactivity to adenosine diphosphate and long-term ischemic event occurrence following percutaneous coronary intervention: a potential antiplatelet therapeutic target. Platelets. 2008;19(8):595-604. 